Seção III - Ensino de geografia: dimensões práticas para o cotidiano em sala de aula

\title{
O porto de santos, vivências, percepções e sentimentos além dos muros da escola: um relato de esperiência e prática
}

\author{
Gilsélia Lemos Moreira
}

\section{SciELO Books / SciELO Livros / SciELO Libros}

MOREIRA, G.L. O porto de santos, vivências, percepções e sentimentos além dos muros da escola: um relato de esperiência e prática. In: TRINDADE, G.A., MOREIRA, G.L., ROCHA, L.B., RANGEL, M.C., and CHIAPETTI, R.J.N. Geografia e ensino: dimensões teóricas e práticas para a sala de aula [online]. Ilhéus: Editus, 2017, pp. 219-235. ISBN: 978-85-7455-526-3.

https://doi.org/10.7476/9788574555263.0014.

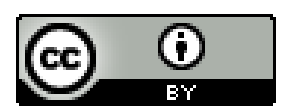

All the contents of this work, except where otherwise noted, is licensed under a Creative Commons Attribution 4.0 International license.

Todo o conteúdo deste trabalho, exceto quando houver ressalva, é publicado sob a licença $\underline{\text { Creative Commons }}$ Atribição 4.0. 


\section{O PORTO DE \\ SANTOS, VIVÊNCIAS, \\ PERCEPÇÕES E \\ SENTIMENTOS ALÉM \\ DOS MUROS DA \\ ESCOLA: um relato de \\ esperiência e prática}

\section{Gilsélia Lemos Moreira}

\section{CONSIDERAÇÕES INICIAIS}

Existe um fosso que separa professor e aluno, e os muros da escola não são os únicos que revelam essa separação entre os dois lados. Há também outros muros invisíveis. Temos uma tensão entre, de um lado, a escola com suas formas historicamente construídas, suas infraestruturas, enfim, construída sobre os auspícios de sistema educacional, arcaico e colonizador.

Ao longo dos séculos construímos uma escola repleta de símbolos e significados, mas que não orienta a ação dos indivíduos na direção dos valores éticos e pleno exercício da cidadania. Por outro lado, há a visão dos alunos como indivíduos, ou melhor, jovens que afirmam não encontrar nada de significativo e interessante na escola.

A escola pouco reconhece as relações e interações como práticas sociais que envolvem processos educativos legítimos. Essas relações deveriam acontecer a partir de reflexões sobre o cotidiano, esse seria um caminho possível na formação de alunos capazes de agir com criticidade, responsabilidade e ética.

Os professores podem contribuir, mas a escola tem que reestruturar conteúdos, encontrar formas de reconhecer o potencial dos jovens, e adotar práticas educativas que estimulem a participação dos alunos no cotidiano escolar. A escola deve ir ao encontro das aspirações dos jovens estudantes.

Sendo assim, para não divagar e perder a epígrafe deste alento tempestivo se faz necessário, recuperar o papel socializador da escola, conceber a 
juventude em sua multiplicidade, bem como, dar nova ênfase às políticas públicas educacionais e redesenhar o espaço escolar.

Um caminho possível está no interior da própria escola, o que implica problematizá-la no contexto de um mundo globalizado. Uma escola que pretende inovar e ampliar a sua prática educativa, deve proporcionar aos seus alunos, espaços para discutir a realidade, a fim de avaliá-la, ressignificá-la e finalmente transformá-la. Estimular os alunos a participar de atividades extracurriculares de cunho interativo/educativo pode ser um importante passo nessa direção. Esse caminho nos propõe como horizonte a articulação entre teoria e prática.

A partir daqui, vamos apresentar um relato de experiência e prática com alunos do ensino médio de uma escola da rede privada da cidade de Santos- SP. Estes alunos participaram de um concurso promovido pela Universidade Católica de Santos. O tema do concurso foi "Porto e Meio Ambiente" e teve por objetivo "levar à comunidade escolar, conhecimentos sobre questões que envolvem as atividades portuárias", ou seja, criar uma nova cultura portuária a partir da escola.

Para tanto, a comissão organizadora do concurso realizou uma campanha de sensibilização e mobilização com os alunos da educação básica das redes pública e privada. Essa campanha envolveu dois momentos distintos, sendo o primeiro, um passeio de escuna pelo Canal do Estuário (visualizando os berços de atracação das margens direita e esquerda), cuja intenção, da comissão foi levar os alunos para conhecer o complexo portuário.

Durante a excursão, os alunos puderam ver os terminais do porto mais de perto, os embarques de açúcar e os portêineres em operação. A excursão foi amparada por palestra de biólogos, ecologistas, professores de Geografia e técnicos portuários.

O passo seguinte envolveu a produção de um projeto histórico/cultural sobre o "Porto de Santos". Os alunos deveriam realizar uma pesquisa e propor uma ação concreta que contemplasse, a um só tempo, a relação porto, meio ambiente e sociedade.

A partir daqui, vamos recuperar o projeto elaborado por alunos do $3^{0}$ do ensino médio ${ }^{1}$ que participaram e venceram o concurso. Trata-se de uma pesquisa sob o mote "O porto de santos: vivências, percepções e sentimentos", este estudo aborda a relação cidade/porto/sociedade.

O projeto foi elaborado por um grupo de 6 alunos do $3^{\circ}$ ano do ensino médio do colégio Liceu São Paulo. Turma B do ano de 2009. 
Esse projeto foi estruturado em dez partes. Inicialmente apresenta-se a introdução, nessa parte os alunos realizaram um breve resgate histórico que traz a baila elementos da dinâmica do porto que puderam colaborar na compreensão dos vários processos que se sucederam geograficamente e contribuíram de forma significativa para as transformações do porto.

Na sequência, apresentam "o tema e o problema", nessa parte do trabalho, os alunos elaboraram questionamentos para definir a abrangência de sua pesquisa. Logo após, expuseram os objetivos e delimitaram metas mais específicas, dentro do trabalho. Dando seguimento, apresentaram a justificativa da investigação e, nessa parte, relataram o porquê da escolha do tema e a relevância do projeto.

$\mathrm{Na}$ continuação, expuseram a metodologia de trabalho, seguida da descrição dos procedimentos realizados na execução da pesquisa, e da ação proposta. No prolongamento do trabalho, apresentaram o cronograma de atividades, os resultados e as propostas e, por fim, as considerações finais.

\section{O Projeto}

Tema "O porto de santos: vivências, percepções e sentimentos"

\section{INTRODUÇÃO}

A cidade de Santos, sede da região metropolitana da Baixada Santista, tem uma estreita relação com a região metropolitana da cidade de São Paulo, pois é responsável pelo escoamento da produção industrial desta região através de seu porto, o maior e mais movimentado da América Latina.

O Porto de Santos foi inaugurado em 1892, quando a então Companhia Docas de Santos - CDS, entregou à navegação mundial os primeiros 260 metros de cais numa área denominada Valongo.

Após a inauguração do porto, a cidade de Santos, passou por uma transformação significativa, as mudanças não ocorrem apenas no espaço da cidade, mas no cotidiano da população. De acordo com Porto (2012) (apud VIEIRA e BRECIANI, 2014), "os velhos trapiches ${ }^{2}$ e as pontes encravadas em terrenos de água suja de lodo e fétida, foram substituídos por aterros e muralhas de pedra". O projeto de mudança do porto da baía de Santos para

2 Armazens de depósito de mercadorias para importar ou exportar. 
o seu interior, em águas protegidas, inclusive do ataque de piratas foi de Braz Cubas ${ }^{3}$

O porto de Santos, apesar de ter crescido manteve-se com o mínimo de mecanização, por mais de três séculos, predominava no porto o trabalho braçal. Também não eram salubres as condições sanitárias do porto, fato que resultava no aparecimento de doenças de caráter epidêmico. Sobre essa realidade, Mendes, (1992, p. 2), relata,

Tristes tempos aqueles! De velhos pardieiros erigidos em trapiches alfandegados, tortuosas e alquebradas pontes de construção pré-histórica serpenteavam pelo lodaçal até penetrarem algumas braças nas águas turvas da baía. Sob o tremendo bochorno dos dias estivais, a pele suarenta e escaldante, enxameavam por eles turmas de homens brancos, que a sedução de um El Dorado para tantos enganoso atraíra de além-mar, de envolta com os negros filhos da raça escravizada da África, arquejando todos ao peso de carga de que iam aliviando o bojo dos navios e atestando os trapiches. Os barcos, cuja atracação se apresentava problemática por muito tempo ainda, descarregavam mesmo ao largo, sobre pontões - sorte de velhos cascos aposentados, onde as mercadorias, a troco de grossa armazenagem, jaziam até o dia em que o fisco, cobrando-se as respectivas taxas, permitia seu livre ingresso no território nacional.

De acordo com o jornal Novo Milênio (2006) 4, em razão da precariedade da infraestrutura do porto, os produtos eram empilhados às margens do estuário da Praça da Alfândega no Valongo em pátios improvisados. Esses produtos ficavam expostos às intempéries e consequentemente se degradavam rapidamente. Além disso, as autoridades não garantiam a segurança, durante o desembarque das mercadorias, Por conta disso, marginais saqueavam partes das cargas desembarcadas nas praias do estuário.

De acordo com Torres (2008), melhorias vieram no início da operação da "São Paulo Railway", em 1867, ligando, por via ferroviária, a região da Baixada Santista ao Planalto. Essa operação trouxe sensíveis melhoras, não só ao sistema de transportes de cargas, mas, consequentemente ao comércio e ao desenvolvimento da própria cidade de Santos.

Fidalgo e explorador português. Fundador da vila de Santos (hoje cidade), governou por duas vezes a Capitania de São Vicente (1545-1549 e 1555-1556). É considerado, por alguns historiadores, fundador de Mogi das Cruzes.

4 Matéria publicada no Jornal eletrônico Novo Milênio em 12 mar. 2006. Disponível em: <http://www.novomilenio.inf.br/porto/portohos.htm>. Acesso em: 15 dez. 2014 


\subsection{A mOdernizaÇÃo DAS INSTALAÇÕES PORTUÁRIAS: UM PORTO MODERNO E EFICIENTE}

A cultura do café que se estendia, na ocasião, por todo o Planalto Paulista, atingindo até algumas áreas da Baixada Santista, também contribuiu para a ampliação e modernização das instalações portuárias. De acordo com a Companhia Docas do Estado de São Paulo - CODESP (2009), em 12 de julho de 1888, pelo Decreto $n^{0}$ 9.979, após concorrência pública, o grupo liderado por Cândido Gaffrée e Eduardo Guinle foi autorizado a construir e explorar, por 39 anos, depois ampliado para 90 anos, o Porto de Santos, com base no projeto do engenheiro Sabóia e Silva.

Vale dizer que os concessionários constituíram a empresa Gaffrée, Guinle $\&$ Cia com o objetivo de estruturar o porto. Essa empresa mais tarde passou a se chamar Empresa de Melhoramentos do Porto de Santos e, em seguida, Companhia Docas de Santos. Na década de 1970 a então, Companhia Docas de Santos completou 80 anos na ocasião o jornalista e historiador Rubens Rodrigues dos Santos, lembrou uma notícia da época da fundação da CDS que dizia,

É impossível que o comércio do exterior teime em servir-se do porto de Santos: e nós sabemos que muitas companhias já proibiram que suas embarcações demandem tão infeccionada cidade. Até o próprio governo, reconhecendo o perigo, consentiu que a linha do Lloyd desviasse os seus paquetes dos mares santistas. Ora, se o nosso governo assim procede, o que os estrangeiros não farão? Que fazer? Melhorar as condições higiênicas de Santos (CORDEIRO E MEROLA, 2014, p.483).

A Companhia Docas de Santos por meio de obras de saneamento conseguiu transformar as margens lodosas e fétidas do estuário. Isso significou uma nova fase do porto, onde velhos trapiches e pontes fincadas foram substituídos por aterros e muralhas de pedra. Uma nova via ferroviária e novos armazéns foram construídos. Segundo Matos (2004, p. 2 e 3),

O porto, centro dinâmico da cidade, precisava ser constantemente modernizado e ampliado, a área tornara-se polo de atração para os imigrantes recémchegados. Em Santos, o contingente imigrante, em particular de ibéricos, foi incorporado em serviços 
estratégicos ao funcionamento básico da economia agroexportadora nos armazéns de café e docas, onde exerceram atividades de doqueiros, estivadores, ensacadores e carroceiros.

De acordo com o resumo histórico publicado no site oficial do Porto de Santos (2009),

\begin{abstract}
Em 1980, com o término do período legal de concessão da exploração do porto pela Companhia Docas de Santos, o Governo Federal criou a Companhia Docas do Estado de S. Paulo (CODESP), empresa de economia mista, de capital majoritário da União. Atualmente, o Porto de Santos movimenta, por ano, mais de 60 milhões de toneladas de cargas diversas, número inimaginável em 1892, quando operou 125 mil toneladas. Com $12 \mathrm{~km}$ de cais, entre as duas margens do estuário de Santos, o porto entrou em nova fase de exploração, consequência da Lei 8.630/93, com arrendamento de áreas e instalações à iniciativa privada, mediante licitações públicas5.
\end{abstract}

Alguns problemas ameaçam o pleno funcionamento das atividades portuárias. Segundo alguns críticos o crescimento das exportações do Brasil só poderá acontecer com o fortalecimento institucional, tecnológico e da infraestrutura do Porto de Santos. Apesar dos problemas, desde 1892, o porto não parou de crescer, sobreviveu a diferentes ciclos econômicos do país, até chegar ao período atual com amplo uso dos contêineres, marco da revolução no transporte e manuseio de cargas.

O porto de Santos é responsável pela movimentação de pouco mais de $27 \%$ da carga transportada em nosso país, com hegemonia reafirmada ao longo do tempo. Ele dispõe de uma rede de acessibilidade favorável, cuja cadeia produtiva inclui elementos dentro e fora das fronteiras brasileiras. (MONIÉ; VIDAL, 2006). Além disso, estabeleceu novos recordes históricos, ao fechar $2005 \mathrm{com}$ um total de 71,902 milhões de toneladas movimentadas, 6,35\% acima do verificado em 2004 (67,609 milhões). De acordo com o Jornal A Tribuna ( PORTO..., 2015, p. 1),

5 Site oficial do porto de Santos. Disponível em: <http://www.portodesantos.com.br $>$. Acesso em: 15 ago. 2009. 
As estatísticas da Companhia Docas do Estado de São Paulo (CODESP) também dão destaque às exportações, que em 2005 chegaram a 50,399 milhões de toneladas, 10,02\% acima do mesmo período de 2004. Na movimentação mensal, outra marca inédita. Passaram pelo porto santista 5,716 milhões de toneladas de carga durante o último mês de dezembro, 15,04\% de acréscimo em relação ao mesmo mês de 2004. Os números acompanham os recordes estabelecidos pela balança comercial brasileira. Em 2008, o Porto de Santos teve uma participação de $26,5 \%$ na balança comercial do país (exportações importações), correspondente a 50,9 bilhões de dólares FOB ("free on board"). Em 2009 o Porto de Santos, registrou uma nova marca histórica mensal, 8.309.897 toneladas. Foi apurado, durante o mês de agosto de 2009, o movimento de 130.345 contêineres.

Mais do que nunca, os portos podem ser a porta de entrada para o desenvolvimento da economia de um país. Seus rumos e direções estão orientados para alimentar o sistema produção/consumo. Portanto, é inegável a importância deste modal para a economia do país.

No entanto, a consciência da chamada "cidade portuária" é um processo ainda em construção, que poderá resultar em um novo modelo de gestão do porto, compatível com as necessidades dos sujeitos sociais (trabalhadores e usuários), institucionais (autoridade portuária e governos representados) e habitantes da cidade. É preciso defender a disseminação de uma cultura portuária, se desejamos estabelecer a relação cidade/porto/sociedade.

\section{O TEMA E O PROBLEMA}

Durante muito tempo a cidade de Santos esteve de "costas para o porto", mas isso ocorreu em todas as cidades portuárias do mundo. Isso tinha a ver com o ambiente socioambiental do porto.

As movimentações das cargas geravam um passivo ambiental que envolvia desde poluição, gerada pelo escoamento de água de lastro, até acidentes por conta do derramamento de combustíveis no mar.

Os portos eram considerados ambientes insalubres, por conta da sujeira e do mau cheiro. Era comum se jogar no mar restos de cargas avariadas de alimentos, as ruas no entorno dos portos não eram apropriadas para moradia, por serem considerados locais deletérios e não oferecer condições de habitabilidade. 
A alta concentração de ratos também era associada ao porto. No campo social, a atividade portuária era exclusivamente masculina. Isso vinha a explicar a existência de prostíbulos próximos à zona portuária.

$\mathrm{O}$ ambiente social estava associado ao submundo de crimes, drogas e contrabando. Essas condições foram determinantes para que os habitantes das cidades se afastassem dos seus portos, "dando-lhes as costas".

As administrações portuárias brasileiras, todas federais, contribuíram muito para aumentar o conflito da cidade com o porto, o que dificultou a gestão integrada com os interesses da região e da cidade, pois, estavam distantes das cidades portuárias e pouco investia na relação porto/cidade/ sociedade. O que interessava era a geração de lucro e riquezas.

Mas, isto já vem se transformando gradativamente, com a tendência da estadualização e municipalização dos portos, a gestão dos mesmos está sob o comando dos estados e das prefeituras, ou seja, está mais perto da comunidade, usuária e da própria cidade. Como exemplo, podemos citar os portos mais bem sucedidos do mundo tais como: o porto de Xangai, que se tornou o maior porto do mundo, o porto de Singapura, o porto de Roterdã, porto de Hong Kong e o porto de Busan, também conhecido como Pusan na Coreia do Sul. Outros portos que também servem de exemplo são os de Bremen, Hamburgo, Roterdã, Amsterdã, Antuérpia ou Singapura, é impossível visitar essas cidades sem se notar os seus portos.

Embora venha ocorrendo o retorno da chamada "visão integrada urbana", o que significa, "um novo olhar para o porto", basta investigar, junto à população, a ideia que a mesma tem do porto, e concluiremos que se trata de um espaço, ainda muito estranho à cidade e distante da vida urbana. Resta saber se em curto, médio ou longo prazo, esse estranhamento pode ser equacionado e quais alternativas serão capazes de reestabelecer e fortalecer a relação cidade/porto/sociedade.

\section{Objetivo geral}

1. Este projeto tem por objetivo fundamental levar à comunidade escolar conhecimento sobre as questões que envolvem as atividades portuárias, em nossa cidade, por meio de uma campanha de sensibilização e mobilização dos alunos do nível fundamental e do ensino médio. Nossa finalidade é contribuir com a formação de uma nova cultura portuária a partir da escola. 
3.1 Objetivos específicos

- Assinalar a importância da relação cidade/porto/sociedade no sentido de promover a um só tempo uma nova consciência ambiental.

- Promover por meio de ações práticas a interação cidade/porto/ sociedade com um foco socioambiental principalmente nas escolas.

- Levar à comunidade escolar conhecimento sobre as questões que envolvem as atividades portuárias, por meio da escola.

\section{Justificativa}

Se o porto atua como um ímã permanente na atração de negócios e, nesse ponto, com uma capacidade quase que inesgotável, sua importância é crucial para o desenvolvimento da cidade. Isso porque, inerente ao conceito de porto, encontra-se o conceito de cluster de negócios, gerador de riquezas. Essa realidade significa a capacidade competitiva da região, da cidade, das empresas e, principalmente, dos próprios cidadãos.

No entanto, projetos e ações que assegurem a um só tempo a interação cidade/porto/sociedade com um foco socioambiental são especialmente escassos, principalmente nas escolas. Dessa forma, um projeto que tem por objetivo levar a comunidade escolar conhecimento sobre as questões que envolvem as atividades portuárias, por meio da escola, com o intuito de ampliar a relação supracitada, parece, ao mesmo tempo, oportuno e relevante.

A realização de um projeto que tem como tema central "Porto e Meio Ambiente", convida-nos e nos propicia a oportunidade de realizar balanços, rever teorias, de reconstruir ideias, enfim, de propor práticas intelectuais e socioambientais capazes de promover a interação entre o Porto e a cidade de Santos.

\section{Metodologia de trabalho}

Fizemos levantamento documental e pesquisa em fontes secundárias na internet em sites oficiais, artigos on line, teses e dissertações, e em 
livros especializados. Realizamos reuniões periódicas com professores, orientador e colegas do grupo, para trocar informações. Nesse período, tivemos a oportunidade de interagir com os professores e conhecedores das questões portuárias e assim, expor nossas expectativas e ansiedades no tocante à realização deste trabalho. Interagimos, também, com crianças e jovens não só da nossa escola, mas também de escolas da rede pública.

Desenvolvemos uma ação intitulada "A semana do porto na escola" que incluiu várias atividades tais como: concurso de poesias, teatro, exibição de vídeos, música, oficina de desenhos, exposição de fotografias e concurso de maquetes. Essas atividades foram realizadas com o intuitito de tornar lúdico, a produção do conhecimento bem como afirmar a importância do porto para a nossa cidade. Criamos na escola um espaço de discussões por meio de um ciclo de palestras, contamos com a participação de professores de diversas áreas, biólogos e técnicos do porto.

\section{Procedimentos metodológicos da “AÇÃo” proposta no PROJETO}

- Produção de oficina com as crianças do ensino fundamental em duas escolas, sendo uma da rede particular outra da rede pública de ensino. Esta se traduziu em brincadeiras e representações. As crianças puderam por meio de uma atividade lúdica retratar o "Porto de Santos".

- Exposição de desenhos, contação de histórias, usando os desenhos do porto que as próprias crianças produziram.

- Oficina de redação e poesias com os alunos do ensino fundamental e médio. Chamamos de "varal de poesias". Partindo do pressuposto de que o universo da poesia é muito rico e encantador, propusemos um trabalho lúdico, prazeroso e bastante agradável com as crianças e os adolescentes.

- Leitura das poesias no pátio da escola com premiação. As poesias foram publicadas no jornal da escola. Como forma dar visibilidade ao trabalho das crianças e adolescentes e ao nosso projeto.

- Brincadeiras com jogos interativos tais como: palavras-cruzadas, quebra-cabeça e dinâmica de grupo.

- Por fim, apresentação de uma peça teatral sob o mote "O Porto e a Cidade". 
Cronograma do projeto/ação

\begin{tabular}{|l|l|l|}
\hline Data & Agosto & Setembro \\
\hline 1-15 & $\begin{array}{l}\text { Levantamento documental e pesquisa em } \\
\text { fontes secundárias na Internet e em livros } \\
\text { especializados }\end{array}$ & Semana do porto na escola \\
\hline $15-20$ & $\begin{array}{l}\text { Reuniões periódicas com professores, nos- } \\
\text { so orientador e com os colegas do grupo. }\end{array}$ & Exposição dos desenhos \\
\hline $20-25$ & Semana do porto na escola & Varal de poesias. \\
\hline 30 & $\begin{array}{l}\text { Oficlo de palestras } \\
\text { mental }\end{array}$ & $\begin{array}{l}\text { Jadas, quebraterativos: palavras-cru- } \\
\text { ca de grupo. }\end{array}$ \\
\hline 30 & $\begin{array}{l}\text { Peça teatral "O Porto e a Cida- } \\
\text { de" }\end{array}$ \\
\hline
\end{tabular}

\section{Resultados obtidos}

A participação da comunidade escolar em todas as etapas do projeto e a produção cultural com as crianças e adolescentes nos permite afirmar que alcançamos nossos objetivos. Além disso, criamos na escola um espaço de discussões, envolvendo os alunos do ensino fundamental e médio, os professores, os coordenadores e a direção da escola.

Nosso trabalho ganhou visibilidade na cidade, fomos pra rua, panfletamos na praia, chamamos a atenção com faixas na porta da escola e distribuímos folders nos shoppings da cidade. Nosso esforço e empenho pela disseminação de uma nova cultura portuária nos rendeu o $1^{\circ}$ lugar no concurso promovido pela Universidade Católica de Santos e, consequentemente bolsas de estudos nessa instituição como prêmio.

Todavia, o mais importante foi lançar a "semente" no sentido de contribuir para uma nova relação cidade/porto/sociedade, e nós conseguimos, com o apoio da nossa escola e da nossa orientadora. Os resultados do nosso trabalho parecem indicar que efetivamente estamos na direção certa. Sabemos que ainda existe um longo caminho a ser percorrido, mas seguimos na certeza de que valeu a pena.

\section{DAS AÇÕES ÀS SOluÇÕES: NOSSA POSPOSTA - CRIAR E FORTALE- CER UMA NOVA CONSCIÊNCIA PORTUÁRIA}

Indicamos em curto prazo, campanhas de sensibilização e mobilização dos sujeitos que habitam a cidade no sentido de se criar e fortalecer 
uma consciência portuária por meio de boletins informativos com linguagem clara e inteligível, que veiculados nos principais meios de comunicação alcancem a sociedade.

Em médio prazo, apontamos à urgência do projeto "Porto Itinerante". A ideia é que a autoridade portuária, o poder público, as escolas e as universidades da baixada santista, possam viabilizar visitas periódicas dos alunos ao porto de Santos. Para tanto, será necessário, transporte e profissionais aptos para se comunicarem com o público alvo e, assim transmitir-lhe os conhecimentos necessários ao fortalecimento de uma nova cultura portuária. É preciso aproximar o porto da população, e a escola é sem sombra de dúvida um canal importantíssimo para promover essa articulação.

Em longo prazo esperamos que as nossas indicações possam contribuir para uma mudança de mentalidade principalmente na escola em relação ao nosso porto.

\section{Conclusão do Projeto Elaborado E aplicado PElos alunos}

A partir do estudo que realizamos, concluímos que a imagem do "Porto de Santos" está mudando. Se, no passado o porto era um local insalubre, hoje é totalmente diferente. O porto está com baixíssima capacidade de poluição, devido ao predominante uso do sistema de cargas conteinerizadas.

Os grandes contingentes de mão de obra masculina não existem mais e, a cada dia, são substituídos por recursos humanos especializados, onde a presença feminina é cada vez maior. A consolidação de Santos como um "porto de contêiner" é muito importante para a cidade, pela capacidade de abranger um grande número cargas diferentes, muitos usuários e múltiplas atividades associadas.

Programas foram implantados para reduzir o nível de poluição gerada pela queima de combustíveis por navios e caminhões com oferta de novas fontes de energia para os terminais, maior controle sobre as águas de lastro dos cargueiros e sobre os efluentes líquidos no estuário.

Apesar dos avanços, nosso porto ainda demanda muitas obras de infraestrutura e está longe de ser um porto excelente. De acordo com Gireli, Vendrame (2012) suas fragilidades no acesso terrestre e marítimo lhe renderam o título de quarto pior porto do Brasil, com nota 5,7, segundo o ranking elaborado pela Coppead envolvendo cerca de 300 empresas exportadoras, armadores e agências marítimas. Mas ressaltamos que, de acordo com a 
nossa pesquisa, muito vem sendo feito para aperfeiçoar o funcionamento do nosso porto.

Não obstante, a sua intensa especialização tem afetado sua relação com a cidade, acentuando o distanciamento entre eles, por isso, em nosso trabalho propusemos por meio de ações concretas, aproximar o porto e a escola. Para que se fez necessário, antes de tudo, desenvolver uma pesquisa histórico/documental. Pois, apesar de vivermos em uma cidade portuária pouco sabíamos a respeito do porto.

Não foi fácil desenvolver as ações previstas em nosso projeto. Apesar da disponibilidade e prontidão da coordenação da escola, da nossa orientadora e dos nossos professores, enfrentamos algumas dificuldades durante a realização do trabalho. O maior problema que encaramos foi conciliar as atividades escolares - provas, exercícios domiciliares e preparação para o ENEM com as ações do nosso projeto.

Isso, fez com que alguns dos nossos colegas se sentissem desestimulados a participar do projeto. Por isso, no início dos trabalhos a participação dos colegas foi tímida. Para vencer esse obstáculo foi imprescindível realizar várias reuniões para sensibilizá-los.

Outra dificuldade foi documentar as atividades do projeto. Não pudemos fotografar as crianças, durantes as oficinas, devido aos direitos autorais. Alguns pais não permitiram. Mas, apesar dos impedimentos encontrados, foi válida a experiência. Esperamos que nosso trabalho tenha continuidade, não somente em nossa escola, mas em todas as outras escolas da Baixada Santista, e que as nossas dificuldades em conciliar atividades extracurriculares com as atividades diárias da escola seja um exemplo para se pensar o tipo de escola que queremos - conteudista ou formadora de cidadãos?

\section{ConsideraÇÕes FINAIS}

Como conclusão da atividade extraclasse aqui relatada, podemos retirar algumas considerações de importante respaldo analítico. Do ponto de vista dos alunos da educação básica, é fundamental que tenham a experiência da iniciação a pesquisa, ao exercício do livre pensar, com isso quero dizer que uma das principais características do ambiente escolar não é tão somente a difusão de conteúdos, mas principalmente a formação de jovens para a vida.

A oportunidade de coordenar esse trabalho nos conduziu ao exercício da reflexão sobre a prática docente. A mobilização dos alunos por 
meio de oficinas de poesias, desenhos, construção de maquetes, produção de vídeos e fotografias, sugerem o impacto positivo dessas atividades na vida dos alunos da educação básica.

O projeto Cidade/Porto permitiu, à comunidade escolar o encontro direto com outra realidade que, apesar de tão próxima, muitas vezes é estigmatizada e marginalizada. Além disso, possibilitou o encontro entre os diferentes níveis de educação, ou seja, a escola e a universidade, além de uma melhor compreensão e mudança de visão sobre a relação cidade/ porto/ sociedade por parte da comunidade escolar.

Convém tornar compreensível que, a inclusão de atividades no currículo escolar, que extrapolem os muros da escola, pode se constituir no ponto de partida da promoção de uma aprendizagem significativa, haja vista que "o aprender pode se tornar um prazer", pois o conhecimento, ganha novo sentido para o aluno.

Alegria, criatividade, energia e vontade de mudança, são características marcantes dos jovens na atualidade, mas às vezes essas qualidades são desprezadas por muitos de nós, professores.

As políticas educacionais devem privilegiar a abertura de espaços que facilitem a livre expressão de ideias, "o ouvir e ser ouvido", a construção coletiva dos saberes.

Há dinâmicas mais complexas a serem consideradas, para tanto, a escola deve ser o lócus do encantamento do "mundo", lugar onde os alunos possam conversar abertamente sobre os mais diversos temas presentes no seu cotidiano e debater todo tipo de assunto com a comunidade escolar.

Da construção de novas formas, esse pode ser um dos instrumentos de que precisamos para nos mobilizar na produção de projetos que atendam aos mais diversos anseios, trazendo benefícios não só para os nossos alunos, mas para toda a sociedade.

O momento atual sinaliza, portanto, uma transformação, pois os jovens anseiam por um ambiente descontraído e democrático na escola, ou seja, um lugar onde possam exercer a sua cidadania, conquistar o seu espaço e ser ouvidos. Não há mais clima para a repetição automática, para a falta de contextualização.

Isso significa dizer que ao contrário do que muitos afirmam, atividades extraclasses, por meio de projetos que envolvem ações práticas em consonância com os interesses dos alunos, podem fortalecer a autoestima desses adolescentes e estimulá-los a ter responsabilidades, criatividade, e autonomia para desenvolver a criticidade. 
Portanto, faz-se necessário investir tempo e disposição na elaboração de atividades capazes de auxiliar na construção de uma postura critica, diante do mundo. Essa postura traz como consequência a construção da ideia de cidadania vinculada ao "saber se posicionar no mundo". Essa é apenas uma condição inicial, um caminho, uma possibilidade, e não uma formula pronta. 


\section{REFERÊNCIAS}

ANDRADE, K. R. N. de. Porto de Santos: o surgimento da cultura de resistência à globalização. Revista do Departamento de Comunicações e Artes da ECA, São Paulo, v.1, n. 5, p. 77-84, jan.-abr. 2009.

PORTO de Santos bate novo recorde de movimentação mensal. Jornal A Tribuna, Santos, 27 out. 2015. Caderno de Economia, p. ı. Disponível em: <http://www.atribuna.com.br/noticias/ noticias-detalhe/porto $\% 26 \mathrm{mar} /$ porto-de-santos-bate-novo-recorde-de-movimentacao-mensal/?cHash=7agb9f6841dd4b4a84off55cd102d677>. Acesso em: 15 maio 2016.

CORDEIRO, A., MEROLA, A.; MENDES, V. Territorialidades da interface porto/cidade contexto urbano de santos: um estudo de caso sobre o bairro do Paquetá. In: CONGRESSO IBEROAMERICANO DE ESTUDIOS Y AMBIENTALES, 6. VI, 2014, São Paulo. [Anais...?] São Paulo: [s.n.], 2014.

Disponível em: <http://docplayer.com.br/9508429-Territorialidades-da-interface-porto-cidade-contexto-urbano-de-santos-um -estudo-de-caso-sobre-o-bairro-do-paqueta.html>. Acesso em: 15 maio 16

GIRELI, T. Z. V.; FERNANDES, Rafael. Aprofundamento do porto de Santos uma análise crítica. Revista Brasileira de Recursos Hídricos, São Paulo, v, 17, n.3, p. 49-59, Jul/Set 2012. Disponível em: $<$ http://docplayer.com.br/6895910-Aprofundamento-do-porto-de-santos-uma-analise-critica.html>. Acesso em: 14 maio 2016

MATOS, M ${ }^{a}$ I. Santos de. O porto do café: cidade, cotidiano e trabalho. Revista Estudos Ibero-Americanos, Porto Alegre, v. 33, n. 2, p. 9-26, dez, 2004. 
MENDES, C. P. No tempo dos trapiches. O Estado de São Paulo, São Paulo, 28 jan 1991. Caderno Marinha Mercante, p. 2. MONIÉ, F. VIDAL, S. M. do S. C. Cidades, portos e cidades portuárias na era da integração produtiva. Revista RAP, Rio de Janeiro, v. 40, n. 6, p. 975- 995, 2006.

TORRES, Luiz Fernando Ribeiro. Estudo analítico e operacional da supervia eletrônica de dados: um modelo de gestão eletrônica para os portos brasileiros. 2008. 157p. Dissertação (Mestrado em Engenharia)- Escola Politécnica da Universidade de São Paulo, Universidade de São Paulo, São Paulo, 2008.

VIEIRA, Sirlei Tereza Pitteri, BRESCIANI, Luís Paulo.

Competências territoriais em perspectivas teóricas e empíricas: o caso do Complexo Portuário de Santos, SP. Revista Brasileira de Gestão e Desenvolvimento Regional. v. 11, n. 1, p. 243-272, jan-abr/2015, Taubaté, SP, Brasil. Disponível em www. rbgdr.net/revista/index.php/rbgdr/article/download/1617/436.

Data de acesso: 15/05/16 